\title{
Emprego do Conceito de Custo de Oportunidade na Escolha de Ração para a Produção de Leitões
}

\begin{abstract}
Sandro Marcos Schimanko Especialização em Administração Financeira pela Universidade Estadual do CentroOeste - UNICENTRO Rua Padre Salvador, 875. Santa Cruz. Guarapuava/PR. CEP: 85015-430 E-mail:s.m.schimanko@hotmail.com

Ary Schwans Doutorado em andamento em Engenharia Florestal pela Universidade Federal do Paraná - UFPR Professor Assistente da Universidade Estadual do Centro-Oeste - UNICENTRO Rua Padre Salvador, 875. Santa Cruz. Guarapuava/PR. CEP: 85015-430 E-mail: ari.unicentro@gmail.com

Verônica Eberle de Almeida Doutorado em andamento em Administração pela Universidade Positivo - UP Participante de grupo de pesquisa da Universidade Positivo - UP Rua Prof. Pedro Viriato Parigot de Souza 5300. Cidade Industrial. Curitiba/PR. CEP: 81280-330 E-mail: veronica.eberle@gmail.com
\end{abstract}

\section{RESUMO}

Este estudo tem por objetivo levantar os custos de ração para a criação de leitões a fim de averiguar qual o valor sacrificado com a escolha da opção mais rentável para o suinocultor à luz do conceito do custo de oportunidade. Na produção de leitões, a ração é responsável por cerca de $70 \%$ dos custos e, por isso, qualquer variação pode impactar significativamente no lucro do produtor. Nesse artigo são analisadas três maneiras de aquisição de ração para a produção de leitões: aquisição da ração pronta (industrializada); aquisição do milho para produção na propriedade e, produção tanto do milho quanto da ração na propriedade do produtor. Dada a diferença entre os processos de fabricação destes produtos podem ocorrer variações na qualidade e, por esse motivo, realizou-se teste empírico com os três tipos de ração a fim de averiguar qual destes possui melhor desempenho com os leitões. Considerando os resultados obtidos, é possível afirmar que a ração fabricada na propriedade com o milho produzido pela mesma é a opção mais vantajosa, pois possibilita melhor retorno financeiro ao produtor.

Palavras-chave: Custos. Produção de Leitões. Ração para Leitões. 


\section{ABSTRACT}

This study aims to survey the cost of rations for piglets, to know what the value sacrificed by choosing the most profitable option for the swine producer observing the light of the concept of opportunity cost. The ration is responsible for approximately $70 \%$ of the cost of production of piglets any variation in cost can significantly change the producer's profit. In this paper we present three ways to get rations for piglets: buying it ready in the industry, producing in the property buying the corn, or even producing in the property using the corn produced by it. Due to the manufacture of these products that are so different, their quality can vary, therefore also a test was performed with the empirical three types of rations to see which has better performance with the piglets. With that has come to a conclusion that ration made on the property with the corn produced by the produced by the same is more advantageous because of the better financial returns for the producer being the ration bought the next best option, therefore, is abandoned, becoming the opportunity cost of choice.

Keywords: Costs. Production of Piglets. Feed for Piglets.

\section{INTRODUÇÃO}

No Brasil, a suinocultura tem se profissionalizado cada vez mais devido à alta variabilidade do mercado, não existindo estabilidade no preço pago pelo leitão. $\mathrm{O}$ produtor, com o intuito de manter suas atividades, procura por meio de parcerias a integração junto a grandes empresas industrializadas para suporte à sua produção. Estas grandes empresas, por sua vez, têm adotado estratégias para diminuir a quantidade de produtores integrados (no sistema de parceria) e, em contrapartida, aumentar o número de matrizes por produtor. Dessa forma, a empresa tem melhores condições para assessorar o produtor quanto a possíveis assistências técnicas, podendo diminuir seus custos com logística além de manter a boa sanidade dos animais.

Em decorrência disso, o produtor tem se profissionalizado cada vez mais em seu trabalho, passando a tratar a sua propriedade como uma empresa. O retorno é caracterizado pelo aumento dos índices de produtividade aliado à melhor preservação do meio ambiente. No entanto, dentro desse contexto, o produtor está cada vez mais alienado à empresa integradora, que passa a 'controlar' a sua atividade. 
O baixo preço pago ao produtor tem sido um dos principais fatores que têm feito com que várias granjas encerrem suas atividades, pois o negócio pode vir a tornar-se inviável. Dentro dessa perspectiva, o suinocultor deve encontrar mecanismos para diminuir seus custos de produção para que consiga minimizar o prejuízo ou mesmo consiga aumentar sua margem de lucro. Como a nutrição representa a maior porcentagem dos custos, é notória a possibilidade de cortes nesta área. Isto é confirmado por Bispo, Ferreira e Abrantes (2008) os quais constataram que, em média, diante da avaliação da série histórica dos custos de produção de suíno no Brasil, a alimentação nas granjas corresponde de $65 \%$ a $70 \%$ dos custos de produção. Portanto, a possibilidade de auferir lucro com a suinocultura depende basicamente de um adequado planejamento da alimentação dos animais, o que envolve a disponibilidade de ingredientes em quantidade e qualidade adequada a preços que viabilizem a produção.

O suinocultor tem algumas formas de adquirir a ração para seus animais, tais como: compra do produto pronto de alguma empresa fabricante, compra dos insumos para a fabricação da ração na propriedade ou ainda a produção do principal insumo milho - para então fabricar a ração na propriedade. Se o produtor produzir milho em sua propriedade, poderá utilizar o mesmo na alimentação de seus animais considerando que o custo de produção será menor e, assim, poderá agregar valor ao negócio. Para a fabricação da ração em sua propriedade (independentemente se o milho é produzido na propriedade ou adquirido junto a outras empresas/agricultores) o suinocultor terá custos com mão de obra e frete, além da necessidade de equipamentos como forrageiro e misturador, os quais sofrem depreciação ao longo do tempo. Nesse caso, é necessária também a aquisição do farelo de soja e do núcleo para a produção da ração. Pela outra opção, compra da ração pronta, a indústria é quem arca com os custos da fabricação e os repassa ao cliente final, comprador da ração.

Outro fator a ser analisado é a qualidade entre estes produtos, oriundos de processos produtivos diferentes e, consequentemente, de qualidade diferente - o que impactará no desempenho dos animais. A ração que proporcionar melhor desempenho, 
ou seja, que apresentar melhor conversão alimentar onde os animais ganhem mais peso consumindo a mesma quantidade de ração, terá um custo menor e com isso o produtor terá uma margem maior na sua produção. Nesse contexto, este estudo se propõe a responder a seguinte questão: Qual dos métodos de obtenção de ração para a criação de leitões se mostra como o mais vantajoso ao produtor: comprar a ração pronta ou fabricá-la em sua propriedade?

Este trabalho se propõe a analisar as três formas de aquisição da ração para suínos (comprar pronta; fabricar na propriedade comprando insumos ou fabricar na propriedade utilizando o milho produzido pela mesma) a fim de descobrir qual das opções apresenta o menor custo e, consequentemente, maior rentabilidade ao produtor. São apurados os custos das três opções e, em seguida, é realizado um teste prático para saber qual opção tem o melhor desempenho para com os animais. Após estas etapas, é comparado o custo benefício de cada uma. Como base para este estudo é utilizado o conceito de custo de oportunidade.

O conceito de custo de oportunidade é amplo e pode ser utilizado no processo decisório para ajudar na tomada de decisões, de forma a aperfeiçoar a utilização dos recursos. Também pode ser utilizado como um dispositivo de avaliação e desempenho dos resultados da empresa, pois permite uma comparação entre diferentes alternativas de investimentos.

\section{VISÃO ECONÔMICA DO CUSTO DE OPORTUNIDADE}

O custo de oportunidade tem sua origem nas ciências econômicas visto à escassez de recursos financeiros e, por isso, se faz necessário análise e melhor escolha entre diferentes alternativas de investimentos, desprezando as alternativas menos atraentes e optando-se pela alternativa mais rentável. De acordo com Zago e Pinto (2005), o conceito de custo de oportunidade foi utilizado, originalmente, por Frederich Von Wieser para mensurar o valor econômico dos fatores de produção, onde 
em sua concepção este conceito - custo de oportunidade - representa a renda líquida gerada por um fator em seu melhor uso alternativo.

O melhor uso alternativo de um bem de produção pode ser definido como o quanto de renda a mais seria gerada por esse fator em comparação a outros fatores. Nesse caso a alternativa que apresentar o melhor resultado econômico deverá ser a escolhida. Segundo Maia (2007) a natureza do custo de oportunidade é diferente da natureza dos custos normalmente contraídos pelas pessoas, uma vez que não envolve desembolso. O custo de oportunidade representa o lucro que deixa de ser obtido por não escolher determinadas atividades, rejeitando-se, por variadas razões, alternativas. Sendo assim, o custo de oportunidade pode ser utilizado como uma ferramenta de comparação entre opções. Nessa linha, Oliveira e Pereira (2005) conceituam o custo de oportunidade como sendo correspondente ao valor de um determinado recurso em seu melhor uso alternativo, o qual representa o custo da escolha de uma alternativa em detrimento de outra capaz de proporcionar um maior benefício, ou seja, é o custo da melhor oportunidade a que se renuncia quando da escolha de uma alternativa.

O custo de uma oportunidade representa o quanto se deixou de ganhar se, ao invés da escolha da melhor alternativa, se optasse por outra. O lucro que seria obtido com a alternativa rejeitada é o custo de oportunidade da escolha. Nesse sentido, ressalta-se a importância da tomada de decisão correta e consciente pelo gestor entre as alternativas disponíveis. Toda vez que o conceito de custo de oportunidade for aplicável, este estará diretamente ligado a uma determinada tomada de decisão. Nesse processo, quando analisa várias alternativas o decisor de modo intuitivo ou propositadamente sempre se perguntará se o benefício a ser obtido, em relação ao sacrifício de recursos correspondentes, será o melhor possível nas circunstâncias em que a decisão está sendo tomada. Essa é a exata essência do conceito de custo de oportunidade.

O gerente, na posição de tomador de decisão, deve sempre analisar a relação custo-benefício entre as alternativas possíveis. As dificuldades de uma correta tomada de decisão são ressaltadas por Oliveira e Pereira (2005) que dizem que o problema 
fundamental do processo de tomada de decisão é a escolha de alternativas e, por isso, o resultado de uma decisão é decorrente do confronto entre o benefício gerado pela alternativa escolhida e o benefício que seria obtido pela escolha da melhor alternativa abandonada. A alternativa que apresentar o maior benefício financeiro e o menor custo para a empresa deverá ser a escolhida, uma vez que esta seja a melhor opção a fim de atender aos objetivos da empresa. Santos e Ponte (1998) asseveram que define-se decisão como $o$ ato de escolher uma dentre várias opções, objetivando resolver um problema ou responder a alguma oportunidade. Para que uma decisão ocorra, deve-se ter mais de uma alternativa de ação; a decisão é fruto da necessidade de se optar por caminhos alternativos. O custo de oportunidade requer alternativas que realmente possam ser comparadas e avaliadas para se tomar uma decisão, ou seja, alternativas que sejam excludentes, possíveis, viáveis e existentes para o consumidor.

Outro fator que deve ser considerado no custo de oportunidade é o grau de risco que cada alternativa possui. Maia (2007) afirma que o custo de oportunidade envolve a análise da remuneração oferecida por diferentes alternativas de aplicação. Dessa maneira, é apropriado considerar os graus de risco de cada ação para a tomada de decisão. O grau de risco de uma alternativa pode ser determinante para o gerente no processo de tomada de decisão, pois o risco de uma alternativa pode levar à sua inviabilidade, mesmo que apresente boa remuneração. Gitman (1997) define risco como a possibilidade de prejuízo financeiro ou a variabilidade de retornos associados a um determinado ativo. Com isso, se o ativo apresentar um grande risco de variabilidade de retornos, o gestor deve decidir pela alternativa que apresentar menor probabilidade de risco.

Segundo Clemente e Souza (1997), quando se fala em risco é necessário fazer uma distinção entre situações de risco e situações de incerteza. As situações de risco são aquelas em que os eventos possíveis e suas probabilidades de ocorrência são conhecidos, enquanto que as situações de incerteza são aquelas em que não se sabe quais são os eventos possíveis, ou as probabilidades de virem a ocorrer não são conhecidas. Quando conhece os possíveis riscos, fica mais fácil para o gestor analisar 
as alternativas, mas quando o cenário apresenta-se incerto, é mais aconselhável seguir com cautela na tomada de decisão, optando por alternativas menos arriscadas. Os autores ainda advertem para a possibilidade de existência de uma aversão ao risco, que é dada pela disposição do decisor de abrir mão de ganhos adicionais para não enfrentar maior nível de risco. Diante disso, o gestor pode abrir mão da alternativa que apresente maior rentabilidade por outra que seja menos rentável, mas que tenha um grau de risco menor.

Portanto, a aplicação do conceito de custo de oportunidade é amplo, cabendo ao gestor analisar em que situação ele se encaixa melhor na sua empresa, e em que circunstância poderá ser utilizado. Maia (2007) afirma que o conceito de custo de oportunidade está presente no cotidiano das pessoas, especialmente quando a escolha de uma alternativa exclui o indivíduo dos benefícios proporcionados pelas alternativas rejeitadas.

\section{VISÃO CONTÁBIL DO CUSTO DE OPORTUNIDADE}

O custo de oportunidade não é visto apenas sob o enfoque econômico, apesar de ter sua origem no mesmo, mas possui também seu enfoque contábil. Conforme descreve Martins (2003), o custo de oportunidade é um conceito costumeiramente chamado de 'econômico' e 'não-contábil', o que não justifica a sua pouca utilização em Contabilidade Geral ou de Custos. O custo de oportunidade pode se refletir, na Contabilidade Geral, no fornecimento de informações para o gerente; e na Contabilidade de Custos como elemento de apoio para a tomada de decisão.

Apesar do custo de oportunidade não representar desembolso em uma tomada de decisão em que se aplique o conceito, este poderá refletir nos resultados contábeis da empresa, pois uma decisão errada pode acarretar em perdas financeiras. Wachholz et al. (2005) afirmam existir diferença entre os enfoques do custo de oportunidade, onde o enfoque dado pela contabilidade é a tentativa desta em alcançar maior objetividade 
em detrimento ao enfoque econômico, tendo em vista que a contabilidade fornece informações para auxiliar seus diversos usuários a tomarem decisões.

A Contabilidade é utilizada como sistema de informação para a tomada de decisões. Como o custo de oportunidade auxilia em uma tomada de decisão que pode alterar os resultados financeiros da empresa, a Contabilidade procura dar maior precisão para o custo de oportunidade. Beuren (1993) afirma que na literatura sobre custo de oportunidade é possível observar que as abordagens em nível de contabilização vão de encontro ao conceito de custo de oportunidade, o que implica no distanciamento do conceito original.

A necessidade de alcançar maior precisão em valores na hora da tomada de decisão faz com que outros fatores sejam contemplados pelo custo de oportunidade. Beuren (1993) alerta sobre o uso de custo de oportunidade como juros sobre o capital próprio, quando adverte que do ponto de vista operacional, os autores da área contábil concordam em considerar os juros sobre o capital próprio como sendo um custo de oportunidade, sendo esta uma forma específica (simplificada) de contemplar o assunto. No entanto, existem diferenças de opinião no que se refere à taxa de juros e à base de cálculo a ser utilizada. Isso ocorre em virtude de não se saber o quanto esse capital poderia render em outras aplicações. Em alguns casos as opções não permitem as mesmas taxas de juros e o retorno do capital pode variar; com isso as opções não têm as mesmas condições para a tomada de decisão.

O uso do custo de oportunidade pela Contabilidade se transforma em um desafio, pois deve se levar em consideração a praticabilidade, objetividade e comparabilidade das informações. De acordo com Martins (2006), a literatura contábil indica que a aplicação do custo de oportunidade deve seguir os seguintes passos: 1) Preparação de uma lista exaustiva das alternativas existentes; 2) Cômputo do resultado esperado de cada alternativa listada; 3) Análise preliminar das alternativas listadas, descartando as menos atraentes; 4) Análise complementar sobre as alternativas que não foram descartadas, selecionando a que maximiza os benefícios esperados para 0 agente; 5) Apuração dos resultados da ação implementada; e 6) Comparação entre os 
resultados apurados da ação implementada e esperados da melhor alternativa rejeitada.

Após este processo pode-se chegar a uma alternativa que maximize os resultados para a empresa a qual, depois de escolhida, deve ser comparada com as alternativas desprezadas para verificar se esta foi a alternativa mais apropriada conforme os objetivos estabelecidos.

\section{METODOLOGIA}

Para a realização desse estudo foi utilizado o método estudo de caso que, de acordo com Fachin (2006) considera a compreensão, como um todo, do assunto investigado e onde também todos os aspectos do caso são investigados. Este trabalho também possui variáveis quantitativas que, segundo a autora, são determinadas em relação aos dados ou à proporção numérica. A quantificação científica envolve um sistema lógico que sustenta a atribuição de números para que os resultados sejam eficazes.

O levantamento bibliográfico foi realizado por meio de consulta em livros, revistas, artigos e internet. A pesquisa bibliográfica, de acordo Gil (2002), permite ao investigador a cobertura de uma gama ampla de fenômenos e, conforme complementam Cervo e Bervian (2002) é realizada com o intuito de recolher informações e conhecimentos prévios acerca de um problema para o qual se procura resposta.

Os testes realizados com as rações foram conduzidos em uma granja com 400 matrizes de leitões, localizada no município de Rio Bonito do Iguaçu, no Estado do Paraná. A propriedade possui infraestrutura considerada adequada para a produção e aplica recursos tecnológicos em suas atividades. A propriedade é familiar e utiliza-se de mão de obra de terceiros. A granja trabalha no sistema de integração, em parceria com uma empresa integradora que fornece genética, assistência técnica, medicamento e 
ração e, ao final do processo produtivo, compra os leitões. Ambas trabalham no sistema Unidade Produtora de Leitões (UPL).

O levantamento de dados quanto aos preços dos produtos datam de janeiro de 2010 e são provenientes de cooperativas da região e, por isso, podem sofrer alterações. No que se refere aos custos de produção de milho, estes são baseados no que a propriedade gastou para fazer o plantio da safra 2009/2010. Os custos apresentados não levam em consideração a energia elétrica utilizada na fabricação da ração tampouco os juros sobre o capital.

Para o cálculo da mão de obra não foram adicionados os encargos. Também se considerou o fato de o empregado poder realizar diferentes atividades em detrimento à produção da ração. Não foi realizado teste separadamente para a ração produzida com milho comprado e a ração produzida com milho cultivado na propriedade, pois foi observado o mesmo desempenho dos animais para ambas as opções.

\section{APRESENTAÇÃO E DISCUSSÃO DOS RESULTADOS}

Para a fabricação das rações destinadas à alimentação dos leitões são utilizados ingredientes como: milho, farelo de soja e núcleo. O milho constitui um dos principais componentes para a produção da ração destinada à alimentação dos leitões. Pode ser produzido na propriedade ou adquirido de outros lugares, como cooperativas, por exemplo. No entanto, é preciso atentar para os custos de cada alternativa. No caso da ração fabricada com o milho produzido na propriedade, primeiramente fez-se 0 levantamento de quanto custa a produção desse milho. A propriedade utiliza-se de boa tecnologia para o plantio, com sementes de qualidade e boa adubação. $\mathrm{Na}$ safra 2009/2010 a propriedade adquiriu os insumos de uma cooperativa da região, cujos custos totais para a produção do milho são os apresentados na Tabela 1. 
Tabela 1 - Custo de produção do milho na propriedade

\begin{tabular}{c|c}
\hline Produtos & Custo R\$/hectare \\
\hline Semente & 420,65 \\
Adubo & 330,03 \\
Ureia & 209,90 \\
Tratamento semente & 75,81 \\
Herbicida & 122,30 \\
Inseticida & 18,93 \\
Preparo do solo/ colheita & 229,00 \\
\hline Total & 1406,62 \\
\hline
\end{tabular}

Fonte: Elaborada pelos autores.

O custo total por hectare do milho produzido na propriedade é de $R \$ 1.406,82$, tendo sido produzidas 165,29 sacas por hectare (cada saca contém $60 \mathrm{~kg}$ ). Com estes dados é possível, então, obter o custo unitário por saca, que monta em $R \$ 8,51$. A cooperativa cobra mais $5 \%$ de taxa para a secagem do produto (resultando em $R \$ 8,94)$. O custo com frete para transporte do produto até a cooperativa é de $R \$ 0,80$ por saca. Sendo assim, o custo de produção total é de $\mathrm{R} \$ 9,74$ por saca de milho. Em janeiro de 2010, caso o produtor optasse por adquirir o milho das cooperativas da região, pagaria $R \$ 19,20$ a saca, comparado com os $R \$ 9,74$ se este fosse produzido em sua propriedade.

O farelo de soja, produto resultante da extração do óleo dos grãos de soja é outro componente necessário para a produção da ração. Este produto era comercializado no início de 2010 a $\mathrm{R} \$ 40,00$ cada saca (50 kg cada uma). A Tabela 2 apresenta a descrição dos ingredientes utilizados para a fabricação das rações com seus respectivos custos por $\mathrm{kg}$ de produto. 
Tabela 2 - Custo dos ingredientes

\begin{tabular}{|c|c|}
\hline Produto & Custo R\$/kg \\
\hline Milho comprado & 0,32 \\
Milho produzido & 0,16 \\
Farelo de soja & 0,80 \\
Núcleo fase 1 & 3,65 \\
Núcleo fase 2 & 3,45 \\
Núcleo fase 3 & 3,63 \\
Antibiótico fase 1 & 25,00 \\
Antibiótico fases 2 e3 & 17,00 \\
\hline
\end{tabular}

Fonte: Elaborada pelos autores.

São necessárias três fases de alimentação para o leitão atingir o peso mínimo de venda. Em cada fase a ração tem uma formulação diferente, com um núcleo específico para aquela determinada fase, que é adicionado ao milho e ao farelo de soja. A tabela 3 mostra o custo por kg de ração produzida na propriedade com o milho comprado e com o milho sendo produzido pela mesma, levando-se em consideração os custos dos ingredientes e a formulação da ração nas diferentes fases.

Tabela 3 - Custo por kg das rações fabricadas

\begin{tabular}{l|c|c}
\hline Fases & $\begin{array}{c}\text { Custo kg ração com milho } \\
\text { comprado }\end{array}$ & $\begin{array}{c}\text { Custo kg ração com milho } \\
\text { produzido }\end{array}$ \\
\hline Fase 1 & 1,87 & 1,81 \\
Fase 2 & 1,24 & 1,16 \\
Fase 3 & 0,66 & 0,56 \\
\hline
\end{tabular}

Fonte: Elaborada pelos autores.

A outra maneira de adquirir ração para os leitões é por meio da aquisição desta já pronta, fornecida pela indústria, a qual entrega a ração na propriedade sem nenhum custo a mais para o produtor. A Tabela 4 apresenta os custos por $\mathrm{kg}$ da ração pronta nas diferentes fases de alimentação. 
Tabela 4 - Custo ração pronta

\begin{tabular}{cc}
\hline Fases & Preço por kg \\
\hline Fase 1 & 1,86 \\
Fase 2 & 1,57 \\
Fase 3 & 0,82 \\
\hline
\end{tabular}

Fonte: Elaborada pelos autores.

A ração fabricada na propriedade e a ração comprada pronta apresentam um desempenho diferente com os leitões, pois elas são fabricadas de maneiras diferentes. Em virtude disso, para execução do estudo foram disponibilizados dois lotes de leitões na propriedade conforme apresentado na Tabela 5, para a realização de teste prático com as rações a fim de analisar qual delas daria melhor desempenho com os animais.

Tabela 5 - Lote de leitões para o teste

\begin{tabular}{ccc}
\hline & Ração fabricada & Ração pronta \\
\hline №. de leitões & 42 & 42 \\
Peso inicial & 337 & 337,5 \\
Idade & 28 dias & 28 dias \\
\hline
\end{tabular}

Fonte: Elaborada pelos autores.

Para as opções de fabricação com milho produzido e com milho comprado foram utilizados os mesmos índices de conversão e consumo de ração, pois as mesmas só se diferenciam pelos seus custos e não pela qualidade. O teste teve início no dia 07/01/2010 quando os leitões foram desmamados. Os leitões apresentavam uniformidade e eram sadios. Estes foram alojados em um bom ambiente onde foram concedidas as mesmas condições para ambas as opções. A Tabela 6 mostra como foi o teste com a ração com milho comprado. 
Emprego do Conceito de Custo de Oportunidade na Escolha de Ração para a Produção de Leitões Sandro Marcos Schimanko, Ary Schwans, Verônica Eberle de Almeida

Tabela 6 - Ração fabricada com milho comprado

\begin{tabular}{ccccc}
\hline Fase & kg ração & Custo & Peso leitões & Conversão \\
\hline $1^{\circ}-07 / 01-18 / 01$ & 3 & 5,61 & 442,5 & 1,19 \\
$2^{\circ}-19 / 01-28 / 01$ & 7 & 8,61 & 660,5 & 1,35 \\
$3^{\circ}-29 / 01-11 / 02$ & 15,5 & 10,23 & 1059,6 & 1,63 \\
\hline Total & 25,5 & 24,45 & 1059,6 & 1,48 \\
\hline
\end{tabular}

Fonte: Elaborada pelos autores.

A ração fabricada com milho comprado teve um consumo de $25,5 \mathrm{~kg}$ por leitão, sendo que os mesmos foram vendidos com $25,2 \mathrm{~kg}$ de média. O custo por leitão foi de $R \$ 24,45$. Os leitões foram vendidos no dia 11/02/2010. A Tabela 7 mostra como foi o teste com a ração fabricada com milho produzido na propriedade. Foram utilizados os mesmos resultados do teste com o milho comprado, só houve alteração nos custos, sendo que o custo do leitão nesse caso ficou em $R \$ 22,23$.

Tabela 7 - Ração fabricada com milho produzido

\begin{tabular}{ccccc}
\hline Fase & kg ração & Custo & peso & Conversão \\
\hline $1^{\circ}-07 / 01-18 / 01$ & 3 & 5,43 & 442,5 & 1,19 \\
$2^{\circ}-19 / 01-28 / 01$ & 7 & 8,12 & 660,5 & 1,35 \\
$3^{\circ}-29 / 01-11 / 02$ & 15,5 & 8,68 & 1059,6 & 1,63 \\
\hline Total & 25,5 & 22,23 & 1059,6 & 1,48 \\
\hline
\end{tabular}

Fonte: Elaborada pelos autores.

No teste realizado com a ração comprada pronta, observou-se um consumo de $22,5 \mathrm{~kg}$ por leitão, sendo que os mesmos, ao final do teste, tiveram um peso médio de $24,6 \mathrm{~kg}$, tendo seu custo apurado em $\mathrm{R} \$ 26,82$ por leitão. A Tabela 8 apresenta os dados correspondentes. 
Tabela 8 - Teste ração pronta

\begin{tabular}{ccccc}
\hline Fase & kg ração & Custo & peso & Conversão \\
\hline $1^{\circ}-07 / 01-18 / 01$ & 3 & 5,58 & 461 & 1,02 \\
$2^{\circ}-19 / 01-28 / 01$ & 7 & 10,99 & 660,5 & 1,47 \\
$3^{\circ}-29 / 01-11 / 02$ & 12,5 & 10,25 & 1036,4 & 1,40 \\
\hline Total & 22,5 & 26,82 & 1036,4 & 1,35 \\
\hline
\end{tabular}

Fonte: Elaborada pelos autores.

Com a fabricação da ração em sua propriedade o produtor terá custos adicionais. Dentre esses custos pode-se considerar a mão de obra e a depreciação das máquinas utilizadas, por exemplo. No levantamento dos valores para este estudo considerou-se que a granja fabrica em torno de $50.000 \mathrm{~kg}$ de ração por mês. O rateio da mão de obra foi baseado em um salário de $\mathrm{R} \$ 670,00$ por mês, mais horas extras e comissão, que no caso da granja em estudo chega a cerca de $R \$ 930,00$. São gastos cerca de 10 dias no mês com a fabricação da ração (cerca de $50.000 \mathrm{~kg}$ ). Foram utilizados no teste 1.071 $\mathrm{kg}$ de ração, o que resulta em um total de mão de obra utilizada no teste de $R \$ 6,64$.

$\mathrm{Na}$ depreciação das máquinas foi utilizado o método linear, sendo que a forrageira tem um valor de $R \$ 1.500,00$ e uma vida útil de cinco anos, com valor residual de $R \$ 500,00$. Durante o mês o equipamento processa cerca de $32.500 \mathrm{~kg}$ de milho. Para fins desse estudo, a forrageira moeu cerca de $610 \mathrm{~kg}$ de milho, ensejando uma depreciação de $\mathrm{R} \$ 0,31$. O misturador da ração tem valor de $\mathrm{R} \$ 5.000,00$ e uma vida útil de cinco anos com um valor de sucata de $R \$ 1.500,00$. No mês em estudo, foi misturado $50.000 \mathrm{~kg}$ de ração. Para a pesquisa foi realizada uma mistura de $1.071 \mathrm{~kg}$, o que resulta em depreciação de $R \$ 1,25$ para este equipamento. Estes custos estão representados na Tabela 9. 
Tabela 9 - Custos fixos

\begin{tabular}{cc}
\hline Mão de obra & 6,64 \\
Depreciação forrageira & 0,31 \\
Depreciação misturador & 1,25 \\
\hline Total de custos fixos & 8,20 \\
\hline
\end{tabular}

Fonte: Elaborada pelos autores.

Dessa forma levantou-se todos os custos e despesas inerentes à fabricação deste insumo necessário para a produção e criação de leitões para venda.

Com relação ao pagamento dos leitões, no sistema de integração, a empresa integradora disponibiliza a ração, genética, assistência técnica, vacinas e medicamentos para seus integrados. Porém, se o integrado não utilizar a ração fornecida pela integradora, receberá pelos seus animais o índice de pagamento dos leitões com desconto, os quais são menores, e com isso o integrado receberá menos pelos leitões. A Tabela 10 apresenta estes valores já com o desconto:

Tabela 10 - Índice de pagamento de leitões com desconto

\begin{tabular}{cc}
\hline Faixa de peso & Índice \\
\hline Até $18,0 \mathrm{~kg}$ & 1,55 \\
De $18,1 \mathrm{~kg}$ a $20,0 \mathrm{~kg}$ & 1,60 \\
De $20,1 \mathrm{~kg}$ a $22,0 \mathrm{~kg}$ & 1,45 \\
De $22,1 \mathrm{~kg}$ acima & 0,58 \\
\hline
\end{tabular}

Fonte: Dados do contrato firmado com a empresa integradora.

No entanto, se o produtor utilizar toda a ração fornecida pela empresa integradora ele receberá os índices de pagamento sem desconto, conforme consta na Tabela 11, resultando num pagamento um pouco maior pelos seus animais. 
Tabela 11 - Índice de pagamento de leitões sem desconto

\begin{tabular}{cc}
\hline Faixa de peso & Índice \\
\hline Ate $18,0 \mathrm{~kg}$ & 1,60 \\
De 18,1 $\mathrm{kg}$ a $20,0 \mathrm{~kg}$ & 1,65 \\
De 20,1 $\mathrm{kg}$ a 22,0kg & 1,50 \\
De 22,1 $\mathrm{kg}$ acima & 0,60 \\
\hline
\end{tabular}

Fonte: Dados do contrato firmado com a empresa integradora.

Os índices são aplicados da seguinte maneira: considerando como exemplo um leitão de $24 \mathrm{~kg}$, para cada faixa de peso é utilizado um índice diferente, ou seja, quanto mais o leitão pesar menor é o índice aplicado. Para fins de cálculo foi utilizado como base o preço pago em fevereiro de 2010 , que era de $R \$ 2,40$ por $\mathrm{kg}$. Para o cálculo do leitão de $24 \mathrm{~kg}$, até os $18 \mathrm{~kg}$ (primeira faixa), multiplica-se esse peso (18) pelo preço do quilo vezes o índice, que no caso de pagamento sem desconto é de 1,60, o que perfaz um total de $\mathrm{R} \$ 69,12\left(=18^{\star} 2,40^{*} 1,60\right)$.

O próximo passo é considerar a faixa subsequente, de $18,1 \mathrm{~kg}$ a $20,0 \mathrm{~kg}(2 \mathrm{~kg})$, onde o índice é de 1,65 o qual também deve ser multiplicado pelo preço por quilo, resultando em $\mathrm{R} \$ 7,92\left(=2 \mathrm{~kg}^{\star} 1,65^{\star} 2,40\right)$. Dos $20,1 \mathrm{~kg}$ a $22,0 \mathrm{~kg} \circ$ índice é de 1,50 obtendo, portanto, o valor de $R \$ 7,20\left(=2 \mathrm{~kg}^{*} 1,50 * 2,40\right)$. Acima de $22 \mathrm{~kg} 0$ índice utilizado é 0,60 , no caso do leitão de $24 \mathrm{~kg}$ é apenas mais $2 \mathrm{~kg}$, que dá $R \$ 2,88$. Somando todos estes valores, apura-se que por um leitão de $24 \mathrm{~kg}$ é pago o valor de $\mathrm{R} \$ 87,12$. A Tabela 12 apresenta, de forma simplificada, o cálculo. 
Tabela 12 - Exemplo de pagamento de leitão com $24 \mathrm{~kg}$

\begin{tabular}{cccc}
\hline Faixa de peso & $\begin{array}{c}\text { Preço } \\
\mathbf{R} \$\end{array}$ & Índice & Total \\
\hline Ate 18,0kg & 2,40 & 1,60 & 69,12 \\
De 18,1kg a 20,0kg & 2,40 & 1,65 & 7,92 \\
De 20,1kg a 22,0kg & 2,40 & 1,50 & 7,20 \\
De 22,1kg acima & 2,40 & 0,60 & 2,88 \\
\hline & Total & & 87,12
\end{tabular}

Fonte: Elaborada pelos autores.

Utilizando o mesmo exemplo, mas alterando os índices para o de pagamento com desconto, seria pago pelo leitão $R \$ 84,38$, valor este $R \$ 2,74$ a menos que no pagamento sem o referido desconto. A empresa que compra os animais, além do pagamento diferenciado pela utilização da ração da mesma, paga mais uma bonificação no preço do leitão se o produtor tiver em sua granja alguns itens como sistema informatizado, bons índices de produtividade e itens de biosseguridade.

Essa bonificação só é paga se o produtor apresentar tais itens e estiver utilizando a ração da empresa. Na granja em estudo, esse índice está em 2,97\%, ou seja, essa porcentagem seria paga a mais no preço do leitão se a mesma utilizasse a ração da empresa integradora. No exemplo anterior, o leitão de $24 \mathrm{~kg}$ resultou em $\mathrm{R} \$$ 87,12 , considerando os $2,97 \%$ de bonificação, o preço do leitão subiria para $R \$ 89,70$.

Levando em consideração essas diferentes formas de pagamento dos leitões, os leitões tratados com ração pronta obtêm maior receita, mas esta é a que apresenta maior custo. Com isso, no caso do teste realizado para este estudo, os 42 leitões tratados com a mesma ração gerariam receita líquida de $R \$ 2.645,61$. Já os leitões tratados com a ração fabricada na propriedade apresentariam receita total de $R \$$ 3.612,24. No entanto, cabe ressaltar que os custos de produção são diferentes: na ração produzida com milho comprado existe o custo de $\mathrm{R} \$ 1.035,10$, o que lhe dá uma receita líquida de $R \$ 2.577,14$. A ração fabricada com o milho produzido na propriedade 
tem custo de $R \$ 941,86$, sendo que a receita líquida desta opção é de $R \$ 2.670,38$. $A$ Tabela 13 apresenta estes valores.

Tabela 13 - Receita obtida com os leitões do teste em cada tipo de ração

\begin{tabular}{cccc}
\hline Ração & Custo total & Receita total & Receita liquida \\
\hline Fabricada milho comprado & $1.035,10$ & $3.612,24$ & $2.577,14$ \\
Fabricada milho produzido & 941,86 & $3.612,24$ & $2.670,38$ \\
Pronta & $1.126,44$ & $3.772,05$ & 2.645 .61 \\
\hline
\end{tabular}

Fonte: Elaborada pelos autores.

Sendo assim, a opção de utilizar a ração fabricada na própria instalação apresenta a maior receita líquida para a atividade de criação de porcos.

\section{CONSIDERAÇÕES FINAIS}

Diante do exposto, observa-se que o lucro obtido com a ração fabricada com o milho produzido na propriedade traz melhor remuneração para o produtor, a qual monta em $R \$ 2.670,38$. Este valor é obtido em virtude do baixo custo de produção do milho, que mesmo com um preço de venda menor, não altera a sua viabilidade financeira. $A$ ração comprada pronta da empresa integradora é a segunda melhor opção e isso se deve à bonificação paga pela empresa pelo uso de sua ração, que chega a $R \$ 108,80$ nos 42 leitões do teste. Esta opção apresenta receita líquida de $R \$ 2.645,61$.

A opção da ração fabricada com o milho comprado é a menos aceitável, pois apresenta uma remuneração de $R \$ 2.577,14$, abaixo das demais opções. Isso se deve ao alto custo de produção, pois o milho comprado custa quase o dobro quando comparado àquele produzido na propriedade, e também ao preço diferenciado pago pelo leitão, que enseja na redução de sua receita.

Portanto, a opção a ser escolhida é a ração produzida na propriedade com o milho produzido pela mesma, uma vez que essa opção apresenta uma rentabilidade melhor ao produtor. Pela escolha desta opção o suinocultor terá um custo de 
oportunidade de $R \$ 2.645,61$, que é o valor do ganho com a ração comprada pronta, sendo esta a melhor opção rejeitada.

Esses resultados podem sofrer alterações ao se considerar que a granja pode não conseguir obter acréscimo de $2,97 \%$ sobre o preço de venda, devido não apresentar os requisitos necessários e exigidos pela empresa integradora. No entanto, é possível também considerar que o empregado poderia fazer outros serviços com o tempo gasto na fabricação de ração. Deve-se levar em consideração também o risco que o suinocultor correria ao deixar de trabalhar em parceria junto à empresa integradora, pois na eventualidade de não utilizar a ração pronta, esta ação configuraria no descumprimento do contrato firmado entre eles.

Outro item que pode ser levado em consideração é o prazo de pagamento das rações. Enquanto a empresa integradora concede carência de oito dias para o pagamento, as empresas que fornecem os ingredientes para a fabricação da ração oferecem trinta dias, o que pode ser vantajoso para o produtor, pois este pode entregar o lote de leitão até o vencimento da ração que os próprios consumiram, além de ter esse dinheiro disponível como capital de giro por 22 dias.

\section{REFERÊNCIAS}

BEUREN, I.M. (1993). Conceituação e Contabilização do Custo de Oportunidade. Caderno de Estudos, 8:01-12.

BISPO, O.N.A.; FERREIRA, M.A.M.; ABRANTES, L.A. (2008). Viabilidade Financeira na Internalização da Produção de Ração na Suinocultura. Sociedade Brasileira de Economia, Administração e Sociologia Rural,1-20.

CERVO, A. L.; BERVIAN, P. A. (2002). Metodologia científica. São Paulo, Makron Books.

CLEMENTE, A. e SOUZA, A. (1997). Decisões financeiras e análise de investimentos: fundamentos, técnicas e aplicações. São Paulo, Atlas.

FACHIN, O. (2006). Fundamentos de Metodologia. São Paulo, Saraiva. 
GIL, A.C. (2002). Como elaborar projetos de pesquisa. São Paulo, Atlas.

GITMAN, L.J. (1997). Princípios de Administração Financeira. São Paulo, Harbra.

MAIA, F.J.F. (2007). O Problema dos Custos de Oportunidade na Configuração do Interesse de Agir na Ação de Habeas Data. Conselho Nacional de Pesquisa e PósGraduação em Direito.

MARTINS, E. (2003). Contabilidade de custos. São Paulo, Atlas.

MARTINS, E. (2006). Avaliação de Empresas: da mensuração contábil à econômica. São Paulo, Atlas.

OLIVEIRA, A.B.S. e PEREIRA, C.A. (2005). Preço de Transferência no Sistema de Gestão Econômica: uma Aplicação do Conceito de Custo de Oportunidade. Gestão Econômica.

SANTOS, E.S. e PONTE, V. (1998). Modelo de Decisão em Gestão Econômica. Caderno de estudos, 10(19):43-56.

WACHHOLZ, C.R.; BENETTI, C.; REGINATO, L. e VEIGA, L. (2005). O Preço de Transferência Interdivisional Baseado no Custo de Oportunidade: Uma Contribuição À Gestão de Custos. In: IX Congresso Internacional de Custos, Florianópolis, 2005. Anais... Florianópolis, UCLA, 2005.

ZAGO, A.P.P. e PINTO, K. C. R. (2005). Custo de oportunidade: polêmicas e provocações. In: IX Congresso Internacional de Custos, Florianópolis, 2005. Anais... Florianópolis, UCLA, 2005.

Data de Submissão: 11/03/2013

Data de Aceite: 28/05/2014 